\title{
Modelling hierarchy and specialization of a system of cities from an evolutionary perspective on firms' interactions
}

Mehdi Bida, University of Lausanne, mehdi.bida@unil.ch

Céline Rozenblat, University of Lausanne, celine.rozenblat@unil.ch

\section{Introduction}

The modelling of cities' systems has got now several experiences through the seminal SIMPOP model (Bura et al., 1996; Pumain, 2012; Pumain and Reuillon, 2017; Sanders et al., 1997) and other innovative efforts (Batty, 2007; Portugali, 2011). These models permitted to better understand the driving forces leading to the formation of cities' system hierarchies based on their interactions. However, none of these models is based on the interactions between micro agents. They all start from some assumptions of interactions between cities, thus between already established groups of agents. The question remains open on how cities and cities' systems that are characterized by hierarchical and diversity properties, emerge from the micro-processes of interacting micro economic agents (Lane et al., 2009; Pumain, 2006a).

The complex approach of cities through micro economic agents needs to be grounded both in evolutionary theory of urban systems (Pumain, 2006b) and in the theories of evolutionary economic geography (Boschma and Martin, 2010), in order to integrate together the general meso and macro properties of co-evolving cities and the assumptions on self-organized economic agents (firms), such as bounded rationality and path dependence (Nelson and Winter, 1982).

The paper proposes a first elaboration of such bottom-up model where cities' systems represent a general meso and macro level constraining environment for micro-agents (firms), while interactions between evolving innovative firms transform this cities' systems environment. The bottom-up approach of cities is firstly questioned (part 1), enabling to introduce the built model (part 2) and to interpret and discuss a set of simulations exploring several variations of competition and distance effects (part 3).

\section{Bottom-up approach to systems of cities}

Even if there is no clear definition of complex systems (Ladyman et al., 2013), cities and the system they form are generally taken to be a good illustration of what complex systems are. Indeed systems of cities are seen as the result of a self-organization of many interacting individual agents (Pumain et al., 2009). These are for example, firms, workers, consumers, etc. when looking at systems of cities through the economics' lenses. Cities and the system they form are thus structures of individual agents that interact in a particular pattern of which spatial agglomeration and other structural properties are the mere manifestation. 


\subsection{Cities as multilevel complex systems}

Usually three levels of organization are identified in the study of systems of cities (Pumain, 2006b): the micro level at which individual agents are considered, the meso level at which individual cities are considered, and the macro level at which a whole system of cities is considered. In terms of a pure set approach, one can designate any element of high level (meso or macro) as a subset of intensely interacting elements of the micro level. The obvious incompleteness of this approach shows the importance of the interaction processes and the resulting organization in defining the levels of observation as more than arbitrary levels of observational aggregation. As a starting point, elements of the meso and macro level have their constituents that interact more with each other than with the constituents of other elements. Moreover, the observed organization at a higher level shows that these local interactions generate the patterns of the higher level interactions thanks to which this higher level organization is observed. Thus, higher level elements are not only constituted by more intensely interacting elements, but their interaction has a particular pattern that creates the higher level organization. In the case of systems of cities, the local interactions between micro agents (firms, workers, consumer, etc.) create cities, that themselves self-organize, into the systems of cities.

\subsection{Understanding urban systems: the interest of a micro-founded approach}

If cities and the systems they form are the result of the self-organization of individual agents, any model to understand their dynamics that does not deduce them from the behavior and interactions of the individual micro level agents is partial at best. Indeed, if cities can be seen as interacting by competing, or exchanging goods or people as in the SIMPOP models (Pumain, 2012) or some economics models (e.g. Mills, 1967), such interactions remain metaphors as they feature interactions between two abstract entities. The interest of a micro founded approach is to explain such abstractions by the actions of tangible entities that take real actions such as firms or consumers. The result is a more solid grounding in reality of the higher level phenomena on two aspects. The first is an understanding of how these phenomena arise from tangible actions, i.e. through the self-organization of micro agents. And the second is a better understanding of the relations governing the co-evolution of such higher level phenomena, through the unfolding of the chain of downward-upward causation. That is by showing how the change in a higher level property A can, through downward causation, change the lower level properties which in turn re-organize into new structures and change another higher level property B. This can be seen for example in Tabuchi and Thisse (2011) where the authors show how the change in transportation costs (which is a macro property in the model they propose) induces changes in the structure of the system of cities.

In this work, we propose to further examine the micro-macro link with an economic model in line with theories of evolutionary economic geography, particularly concerning regional knowledge. The model is based on micro level interactions of firms and is built using the weakest assumptions we can about the behavior of firms: firms have incomplete information and bounded rationality. The goal is to estimate in which extend the micro-level interactions can make emerge some meso level cities and macro level system of cities observing some specific properties. 


\subsection{The two empirical evidences of hierarchy and specialization and associated theories}

The model focuses on reproducing the two main universal properties of systems of cities: the hierarchical size differentiation and the socio economic specialization (Pumain et al., 2009).

\subsubsection{Urban size hierarchy}

Perhaps the most salient empirical regularity that is observed at the level of the system of cities is the hierarchical differentiation of cities' sizes. Within a same system (usually the cities of a same country that are supposed to have strongly interacted for a long time), cities sizes (usually the city's number of inhabitants) have been observed to follow approximatively a Pareto distribution with a great consistency across time and countries (Brakman et al., 2009; Rosen and Resnick, 1980). This fact was first observed at least as early as 1913, when Auerbach (1913) observed that the product between the rank of German cities and their population is approximatively constant. Later, Singer (1936) observed for several countries (e.g. France, U.S.A, Germany) and dates, that the distribution of their cities' sizes was close to the Zipf distribution:

$$
\operatorname{Probability}(\text { Size }=k)=A k^{-\beta}, \beta>0 .
$$

The observation was eventually made famous by Zipf (1949), when he noted the same relation between the size and rank of cities in several countries as part of his more general research on what later became his eponymous distribution. The level of the size hierarchical differentiation is usually examined by looking at the relation between the size of cities and their rank when the sizes are ordered in a decreasing order. The relation should be close to log-linear when the size is approximatively Zipf distributed ${ }^{1}$ (Fig.1).

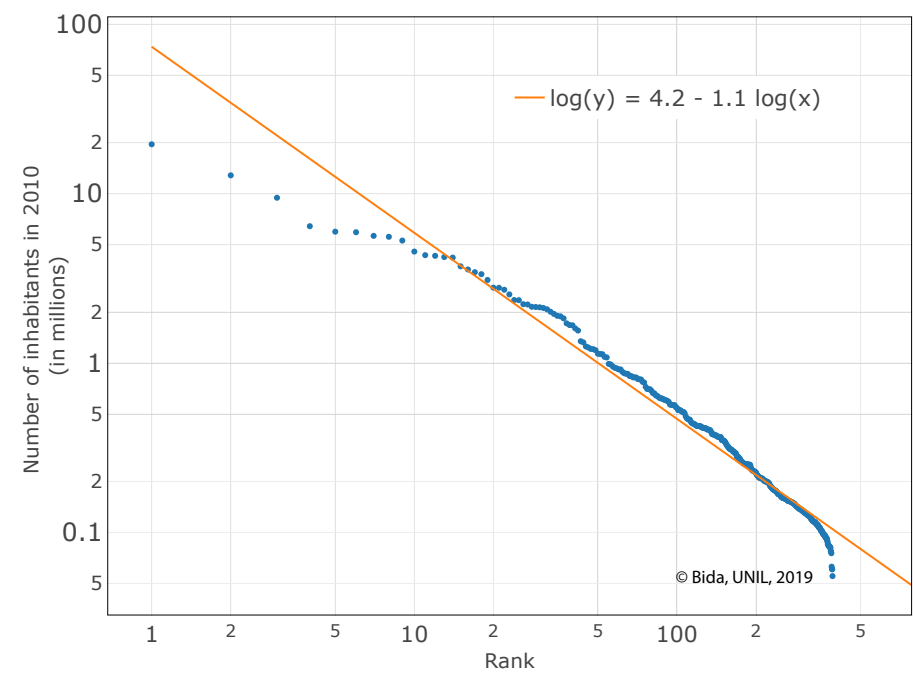

Figure 1: Size distribution of US metropolitan statistical areas in 2010 (source: U.S. Census Bureau)

\footnotetext{
${ }^{1}$ Although more recent models succeed at generating distributions that fit better the empirical observations (Duranton, 2007; Giesen and Suedekum, 2012), it remains interesting to use Zipf's distribution as a benchmark when modeling processes that seek at reproducing urban hierarchies without confronting it to data about existing urban systems.
} 
Although Zipf himself insisted on the fact that the city size is proportional to its rank $(\beta=1)$, the empirically observed values of $\beta$ range actually from 0.48 to 1.22 depending on the country and the used definition of city (Brakman et al., 2009). Higher $\beta$ coefficients indicate a stronger differentiation between the cities' sizes, that is a more important difference between cities of two different ranks.

Modeling the processes that lead to a Zipf distribution of city sizes have received great attention from geographers and economists. We quickly review here the different categories of models based on the main idea proposed to explain the city sizes distribution, for a deeper discussion of the question, the reader can refer to Pumain (2006), Brakman et al. (2009), and Dimou and Schaffar (2011).

A first category of models is based on purely random processes suggested by Gibrat (1931). Gabaix (1999) was among the first economic models that was shown to generate a Zipf distribution. Gabaix considers cities randomly growing at a common mean rate, with their growths rates being independent across cities and time. Despite the discrepancy between the model assumptions and empirical observations (Pumain et al., 2009), an interesting conclusion can be drawn from Gabaix's work regarding the process that governs the growth of cities. If the growth rate is random and independent and if there is no mechanism that prevents cities from indefinitely shrinking, then the resulting distribution will necessarily be degenerate. The consequence of this is that either the growth rates are not independent or their mean is not proportional to their size.

A second category of models, from mainstream economics, proposes that Zipf like distributions of cities are the result of an equilibrium between agglomeration and dispersion forces. Brakman et al. (1999) took into account the congestion costs in order to avoid to agglomerate all the population in a single city as in Krugman's model (1991). Eaton and Eckstein (1997) consider dynamic growth of cities of which steady state results in a Zipf like distribution, the model features knowledge spillovers between cities.

A third category of model is based on spillovers or diffusion, where cities' growth is dependent on their own size, but also on the size of the other cities in the system through a spillover mechanism. The spillover avoids the situation where a small subset of cities grow too fast compared to the other cities of the system. Although belonging to two different modeling traditions, the SIMPOPlocal model (Pumain and Reuillon, 2017) and Duranton (2007) share the reliance of this common mechanism.

Thus, in order to generate a Zipf like distribution, it seems that the growth advantage due to city size whether it is in the form of agglomeration economies or increasing returns to scale, should be compensated by the presence of dispersion forces or intercity spillovers.

\subsubsection{Cities' economic specialization}

A second property of system of cities appears in their division of labor at this macro-level leading to the relative specialization of each city (Aydalot, 1985). Larger cities have been observed to be generally more diversified than smaller ones (USA: Henderson, V., 1997; Canada: Marshall, 1981; China: Min-rong and Yan-hua, 2013; Japan: Mori et al., 2008) (Fig.2). This pattern, also, is consistent in time and by sectoral composition. Not only cities keep the 
same degree of specialization over time, but also the activities in which they specialize (Duranton and Puga, 2000).

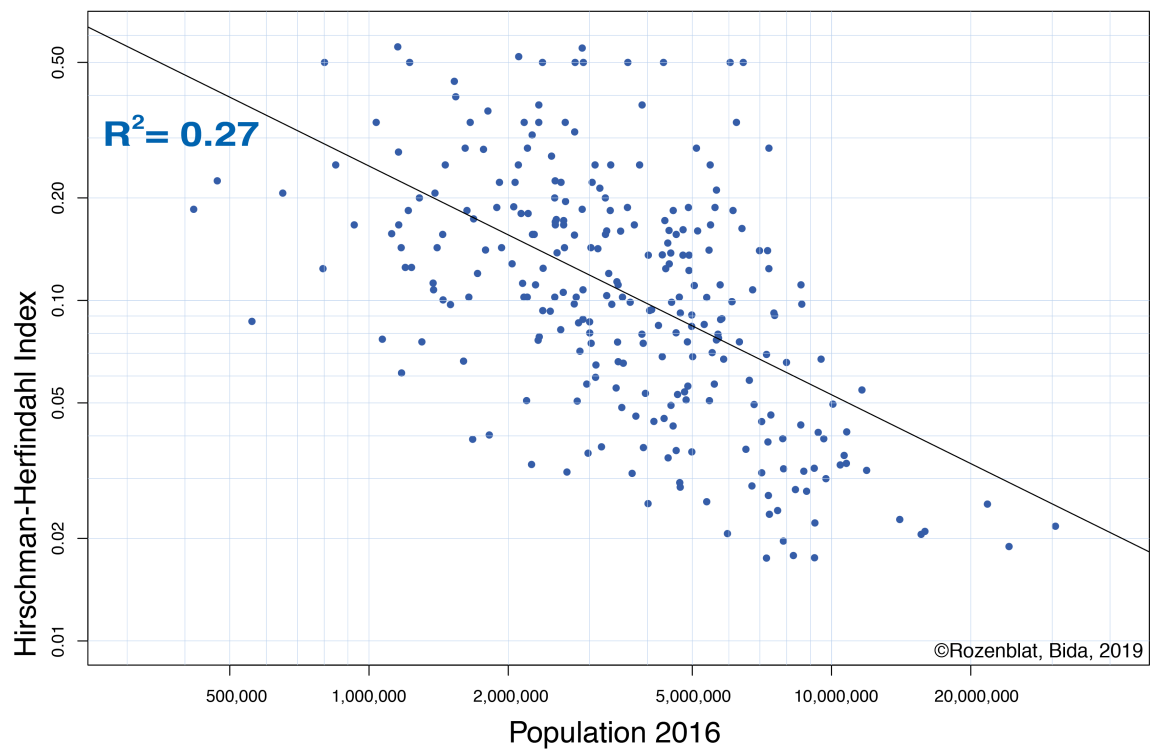

Figure 2: Size and economic specialization for Chinese cities in 2016

If the negative relation between size and specialization has not received as much attention as the distribution of city sizes, several theories give some possible explanations to this observed relation. Static economic theories explaining this facts either emphasize the role of the advantage to economic diversity (Davis and Dingel, 2014), or the interaction between transportation costs, internal increasing returns and competitive pressure (Tabuchi and Thisse, 2011) as an extension of the central place theory (Christaller, 1933; Lösch, 1954).

Dynamic theories seem however more appealing, as they exhibit the processes through which cities become more diversified as they grow. In this line, Pumain et al. (2009) propose a model of urban diversification based on the unequal diffusion of innovations throughout the system of cities. New industries are created through successive innovation waves, which are better captured by bigger cities, and then selectively diffuse to smaller cities depending on the availability of the local resources (physical or knowledge). This model appears as a plausible consequence at the cities' system level of the findings of evolutionary economic geography. One of the main findings of latter is that local knowledge is essential in determining regional economic evolution. Indeed, the development of the notion of technological relatedness has shown how the growth of regions happens primarily through related diversification (Boschma, 2017). Related diversification stands for the fact that the emergence of new activities in a region is strongly dependent on the nature of the present activities. In particular, empirical studies such as Neffke et al. (2011) have shown that the new industries that develop in a given region are predominantly technologically related to the region's current industries.

\section{The model}

The micro founded model aims at reproducing the two main observed properties of systems of cities: the size hierarchy and the pattern of economic specialization, through micro interactions between firms. To this end, the model features interactions between micro level 
agents: firms in the context of the meso level of cities and of the system of cities acting on the micro level of firms' interactions. In return, cities and the system of cities are transformed by the results of the micro interactions between firms.

\subsection{General description}

The bottom-up model is compatible with the evolutionary framework in the sense that at the micro-level, firms are endowed with bounded rationality (myopic optimization) and have their capabilities evolve through time with the possibilities of innovation (Fig.3).

\begin{tabular}{|l|l|l|}
\hline \multirow{2}{*}{ MESO (CITY) } & \multicolumn{2}{|l|}{ Inherited Cities' industrial mix } \\
\hline \multirow{3}{*}{ MICRO (FIRM) } & INDIVIDUAL & \multicolumn{1}{|l|}{ INTERACTIONS } \\
\cline { 2 - 3 } & Innovation & $\begin{array}{l}\text { Trade } \\
\text { Competition } \\
\end{array}$ \\
& Myopic optimization & Selection \\
\hline
\end{tabular}

Figure 3: Main concepts of the model

Firms exchange each other by trade, but also compete within the same industry, a selection operating among the less competitive ones. At micro and meso-level, the model features path dependence by the fact that the presence of firms with certain industries in a city creates an inherited industrial mix that changes the possibilities of its future evolution by: 1) influencing its wealth and size and by 2 ) influencing its future path in the technological space (future entries of firms). The functionning of the model integrates micro, meso and macro levels (Fig.4).

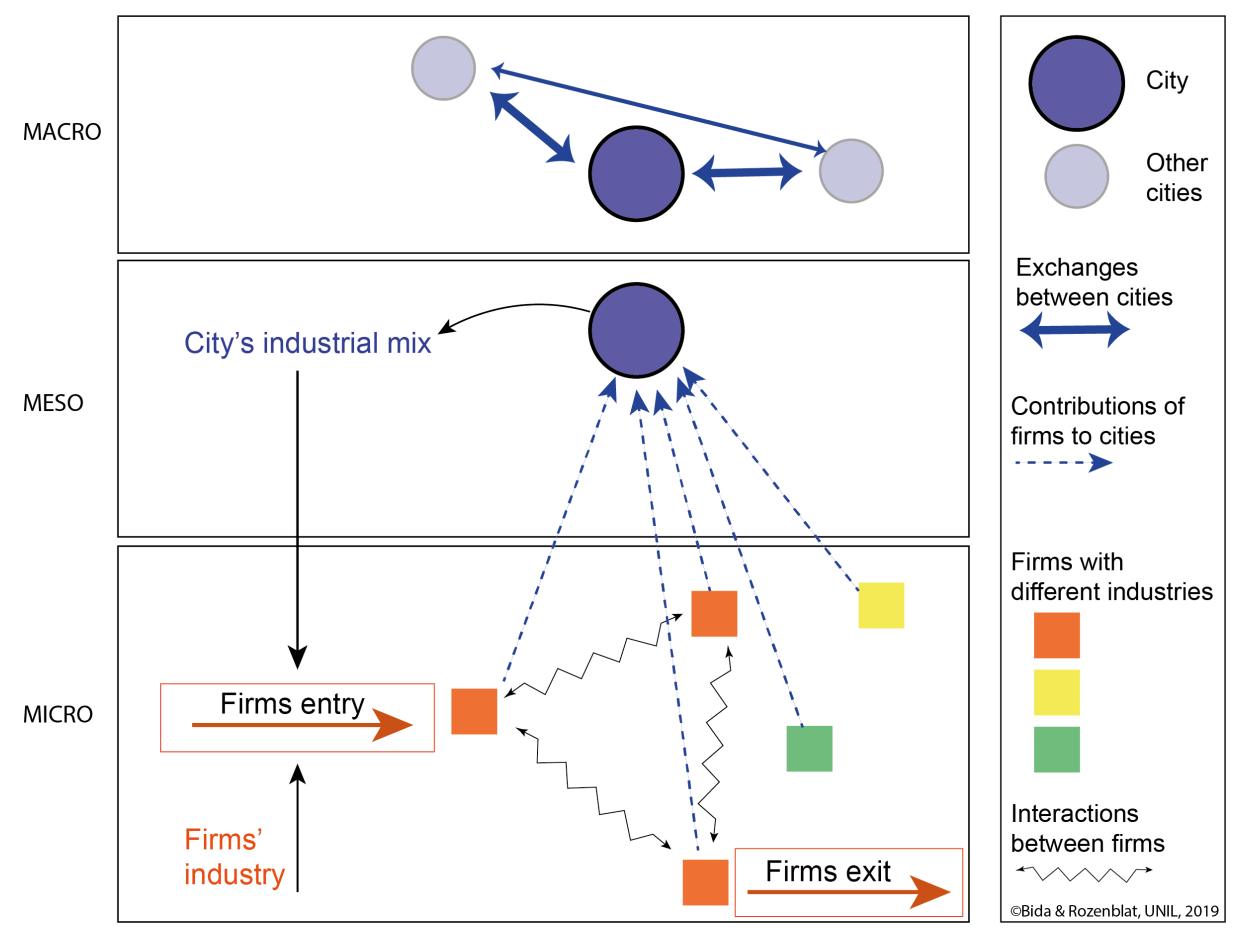

Figure 4: Functioning of the model 
In line with the idea of related diversification, the probability that a firm of a given industry enters (micro level) depends on the current industrial mix of this city. This is because we assume that a firm belonging to a certain industry has to tap into local competences in order to produce, which is impossible if the local competences are inadequate to the firm's need.

We assume that initially, every city is endowed with a particular industry, and that the relatedness between industries is uniformly distributed so that no city is initially advantaged. Every iteration corresponds to a trade phase, a phase where firms improve their production process and a phase where new firms enter the market. Interactions between firms consist here only in market competition between firms of the same industry. Over the iterations, cities enrich their industrial mix (meso-level in Figure 4) through the entry of new local firms that belong to related industries conferring them competitive advantage if the industry is still profitable (otherwise money-loosing firms exit according to the selection process). The hierarchical diffusion of innovations is embodied in the two following processes: largest cities have a higher likelihood to host new undiscovered industries (because they have a more diverse industrial mix). Once they discover a new industry, cities hosting existent related industries can easily host a new firm belonging to the newly discovered industry.

This model reveals sufficient to generate the desired properties of systems of cities (macrolevel). The exchanges between cities consist in the sum of the trade flows between firms of cities and other cities' consumers. Such flows also exist inside each city, but does not change the city income (which is consistent with the economic base theory, where local exchanges are only considered as induced activities without any influence on the wealth of cities). In order to implement this model, few variables and parameters are necessary (Fig.5):

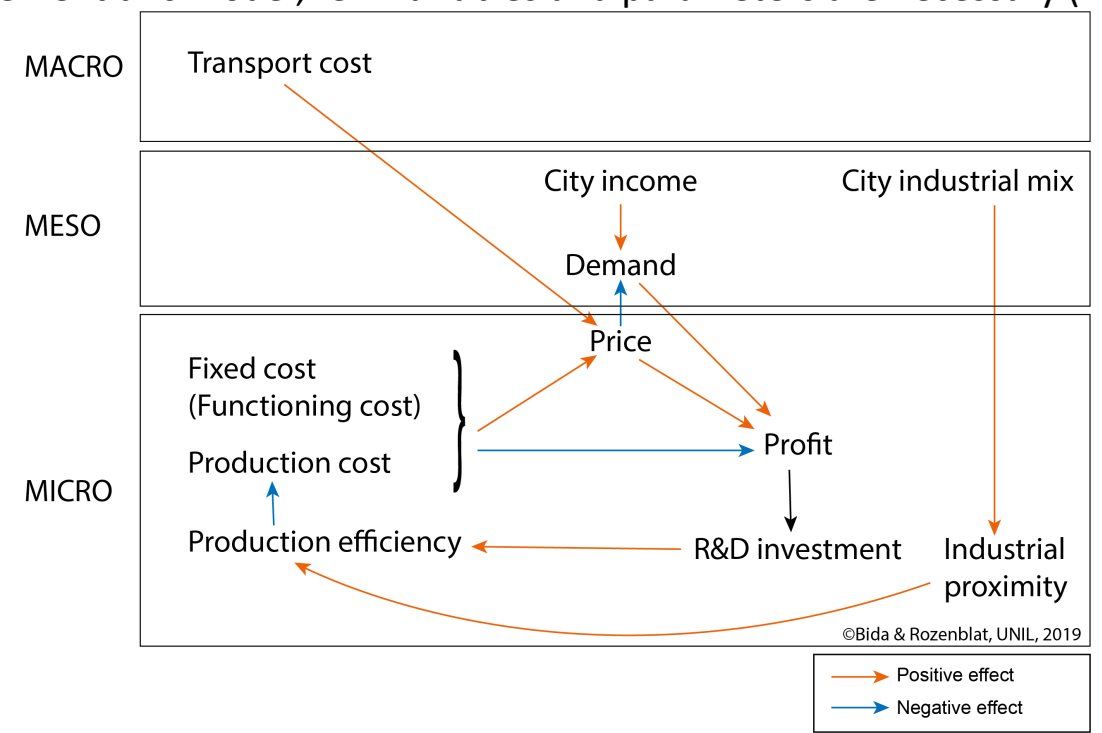

Figure 5: Variables of the model

At the micro-level:

- Each firm faces a fixed cost (its functioning) and production cost which depends on the innovative level reached at one moment by the firm (Production efficiency).

- The production efficiency increases thanks to the R\&D investment procured by the profit made at the previous step. It increases also thanks to the location economies realized through the industrial proximity permitted by the city industrial mix (mesolevel) reached at the previous step. 
- The profit of each firm depends of the fixed cost and production cost (negatively) and on the combination of the price and the amount of the demand.

- The price determined by each firm depends on the costs of the firm (micro-level) but also on the transportation costs which is define at the macro-level.

At the meso-level:

- The demand itself depends on one hand on the price, but also on the city income (meso-level);

At the macro-level:

- Transportation costs are fixed and similar for all firms and across the city system.

As a result at the macro-level:

- Hierarchy of cities size will emerge from the micro/meso interactions;

- Specialization of cities also contributes to qualify the division of labor within the urban system, that will be qualified by heterogenous levels of cities' specialization.

\subsection{Formal description}

The modelling framework is roughly based on the standard dynamic micro-economic framework of which some assumptions are relaxed. The model features firms and consumers that are located in cities. Firms compete within a same industry to sell their good to consumers located in all cities and function using only local labor. New firms randomly enter each time step. The entry success of new firms depends on the proximity of their industry to the city industrial mix. Nor positive neither negative externalities are accounted for in this model. In particular cities are neither subject to congestion cost nor to external scale economies. However the model rests on the meso-level effect that is the dependence on the current industrial mix, of the probability of entry and the level of efficiency of new firms.

\section{2.a Cities and consumers}

We assume that initially, there is a finite number $V$ of cities. The cities are spatially located in a finite one-dimensional isotropic space. We choose to place the cities on a circle of length $L$ to avoid any boundary effects (Figure 6). We furthermore assume that they are regularly spaced, so that no particular subset of cities can benefit of be disadvantaged by the irregularity of their spatial distribution. We however note that the regular spacing of the cities is not a definite feature of the urban system, as the model allows cities to decay and completely disappear.

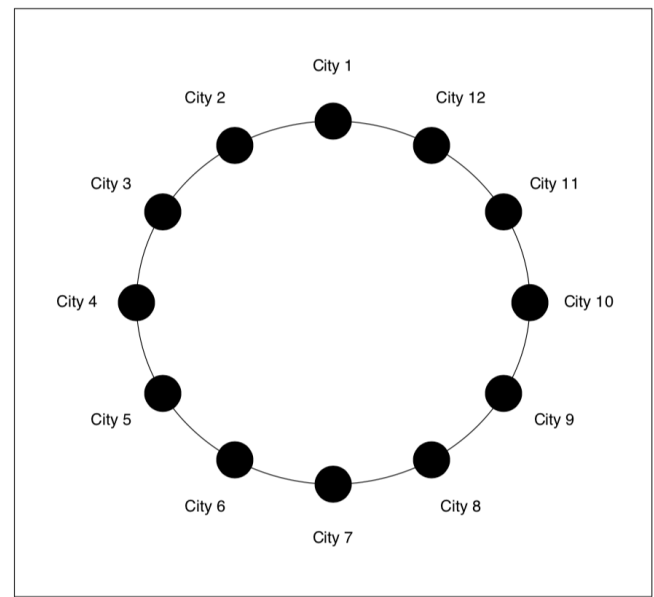

Figure 6: Example of initial configuration with 12 cities 
Cities are characterized by their income that is the sum of their firms' previous revenues, since firms only employ local labor. All this income is used to buy goods from active firms at the next iteration. For the sake of simplicity, we assume that the income of each city is evenly spread over the active industries. On the aggregate level, for a same industry, consumers do not favor the product of a firm over another, and thus the attractiveness of a product within an industry only depends on its price. Given these requirements, we choose the aggregate city-demand to be:

$$
q_{i j}=\frac{C_{j}}{N} \frac{p_{i j}^{-\alpha}}{\sum_{i \in I} p_{i j}^{1-\alpha}}, \alpha>0,
$$

where $C_{j}$ is the income of city $j, N$ the number of active industries (with operating firms), $p_{i j}$ is the price of firm $i$ to consumers located in city $j$, and $\alpha$ a parameter that determines the sensitivity of the consumers to the relative price level. The choice of the constant elasticity of substitution function is motivated by the ability of this function to represent a variety of aggregate consumer behavior: from a choice only motivated by the price level (high values of $\alpha)$ to the case where each firm has its own consumption niche ( $\alpha$ close to 0 ).

\section{2.b Firms and industries}

There exists a finite number $I$ of industries to which firms can belong. Not all industries need to be active. An industry is considered as active when at least one firm belonging to it is active. Industries determine the type of good that is produced by firms, one can think of it as an abstraction of economic sectors. All the firms that belong to a same industry produce a homogenous good, and are directly in competition to each other, meaning that the entry of a firm of the same industry will directly impact their market share, whereas this is not the case when firms in other active industries enter the market. However, industries also compete in a certain way: every time a firm belonging to an inactive industry enters the market, it takes a proportion of the city total income shared by existing industries.

In order to implement the idea of related diversification (Boschma and Frenken, 2011), we introduce a level of technological relatedness between the industries. It is a proximity measure that indicates the level of technological relatedness between two industries. We build on the empirical findings about industrial evolution at the regional (Neffke et al., 2011) and the international scale (Hidalgo et al., 2007). Both studies use the concept of industry/product space to represent the technological proximity between the different industries in order to analyze the dynamics of the evolution of the industrial mix of countries and regions. In spite of the difference of scale, both studies present similar findings about the structure of the industry space and the dynamics of industrial evolution. The industry space has been found to be modular, i.e. with groups of industries of high intra relatedness and low inter relatedness. Moreover, regions' as well as countries' industrial mixes have been shown to evolve consistently with the industries' space structure, by remaining closely related to its previous state.

In light of these results we assume that, at the meso level, the current industrial mix of a city will determine the dynamics of firms' entry. More precisely, the level of technological relatedness between the present industries and the industries of potential entrants will determine their probability of entry at each time step. The firms' entries make evolve the city' industrial mix. 
The level of relatedness $\theta_{k l}\left(=\theta_{l k}\right)$ between two industries $k$ and $l$ lies between 0 and 1 , where a level of 1 stands for the highest level of relatedness and 0 for the lowest level of relatedness. A modular industry structure in this case would mean that industries would be divided in groups with very high $\theta$ for two industries within the same group and very low $\theta$ for two industries each belonging to a distinct group (Figure 7-A). We will depart from this structure and assume that the industries cannot completely be separated into clearly distinct groups, but that each industry is related to a fixed number of other industries constituting a low density quasi-regular industry space (Figure 7-B).
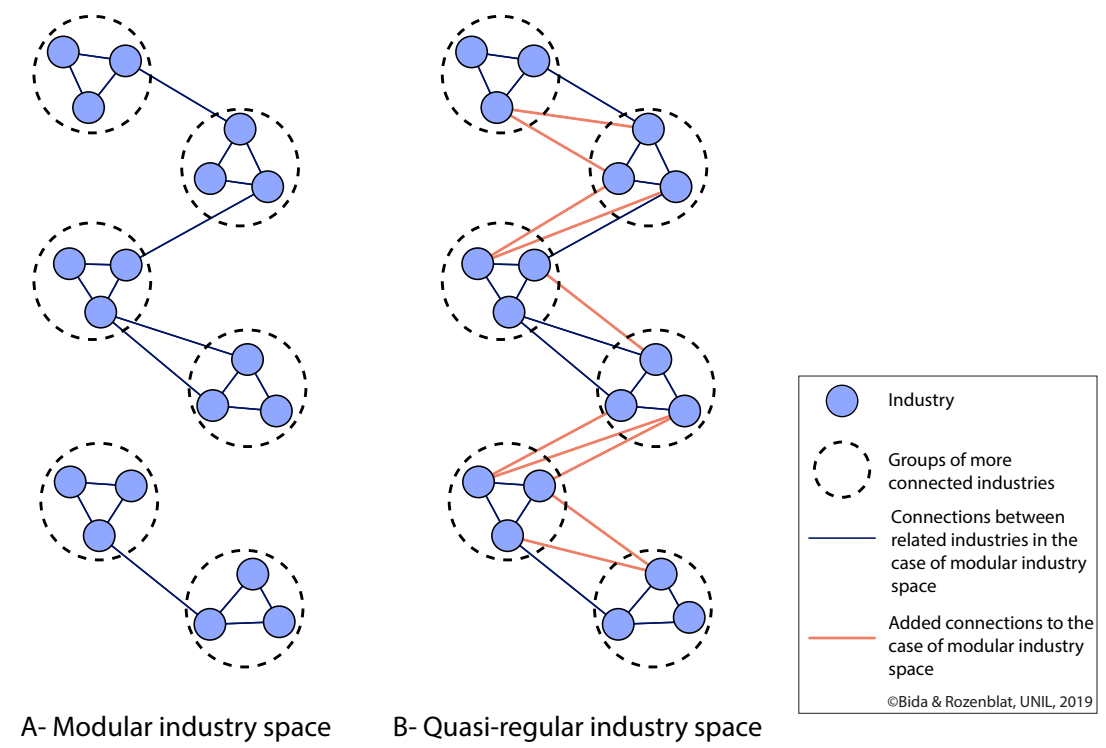

Figure 7: Example of industry space with 20 industries

A- Is a modular pattern, as usually empirically observed B- Is a more connected version of $A$, as taken in the model. Each industry is related to 4 others.

This connection between industry groups will allow cities to discover inexistent industries while preserving the idea that new industries can only be discovered through a definite set of existing industries. Finally, we further simplify the structure by assuming that the relatedness between two industries is either 0 or 1.

Each firm is located in only one city, where it only uses local labor to operate. Firms produce and transport goods to consumers in all cities. A constant level of labor is necessary to the functioning of the firm, and goods are produced and transported at constant return.

Selling goods to consumers located in other cities requires (local) labor to transport them that depends on the quantity and the distance over which they carried. Each firm is moreover endowed with a level of production efficiency that determines the amount of labor needed to produce one good. The amount of labor needed by the firm at each time step is given by:

$$
l_{i}=b_{i}+\left[\sum_{j=1}^{V} q_{i j}\left(a_{i}^{-1}+D_{i j}\right)\right], D_{i j}=\left(1+d_{i j}\right)^{\gamma}-1, \gamma \geq 0,
$$

where $b_{i}$ is a fixed amount of labor to keep the firm functioning, $a_{i}$ is the production efficiency and $D_{i j}$ is the necessary amount of labor to transport one unit of good between producer's $i$ 
city and consumers located in a city $j$ that depends on the distance $d_{i j}$ between the city of producer $i$ and the city of consumers $j$.

In this model, we do not account for the interaction between workers and firms. For simplicity we assume that firms can find all the necessary amount of labor needed in the city where they are located at a constant wage that we set equal to 1 for all industries and cities. In these conditions, the profit of producer $i$ is given by:

$$
\Pi_{i}=q_{i} p_{i}-l_{i}
$$

\section{2.c Initial conditions and dynamics}

In order not to advantage any city, we assume that initially, all cities are endowed with the same income, and host only one firm. All the initial firms belong to the same industry.

At every time step $t$, for each city $j$ and industry $l$, a maximum of one firm enters the market with the following probabilities:

- if the industry already has been or is still active in the economy

$$
\left.\max _{l \text { in city }} \theta_{l k}\right]
$$

- if the industry was never active before

$$
\left.\max _{l \text { in city } j} \theta_{l k}\right] p_{\text {discovery }}
$$

Note here that the more other related industries are present in a city, the higher are the chances of a given industry to enter the city. Over the iterations, we expect this to create a process of related diversification of cities. As cities become more likely to foster an industry as their industrial mix is more related to it. We set two different probabilities for discovered and undiscovered industries to reflect the fact that the emergence of a new industry is much more difficult than the entry of competitors in an established industry. However, the latter still depends on the industrial mix of the city since it requires knowledge resources and supporting institutional structures that have to be available locally (Boschma and Frenken, 2011).

Entering firms belonging to a unprecedently discovered industry enter the market with a level of efficiency equal to 1 . Otherwise, for an already discovered industry $k$, a new competitor $h$ belonging to $k$ a that enters the market is initially endowed with a level of production efficiency $a_{h}$ randomly chosen as:

$$
a_{h}=1+A_{k j}, \quad A_{k j} \sim \operatorname{Binom}\left(\left[\max _{i \text { in city } j} a_{i}\right]-1, \theta_{M(k, j) k}\right),
$$

where $M(k, j)$ is the industry already present in city $j$ that has is the most related to industry $k$. This means that the more related and efficient the current firms in city $j$ are, the more likely entering firms will also be efficient. Note that $a_{h}$ is never higher than the most efficient incumbent of industry $M(k, j)$, which is the industry from which we can consider that $h$ "branched". This is because the efficiency of production is partly acquired through learningby-doing (Thompson, 2010) and thus incumbent firms, which are more experimented, are 
assumed to be more efficient. However, this also implies that cities having very efficient firms in closely related industries can see their entering competitors being more efficient than "unexperimented" incumbents.

Newly entering firms join the market with active firms and trade with the consumers located in all cities according to the equations above. Firms with a negative profit exit the market, and earning profit firms invest a certain constant proportion $q$ of their profit in research and development (R\&D), also employing local labor, in order to improve their production process and raise their level of efficiency. Decisions concerning R\&D investments in general are conditioned by several factors such as the appropriability of the innovation and market structure (Cohen, 2010). Firm size (usually firm revenue) has been empirically shown to explain more than half of the intra-industry variance with which R\&D investments grow below but close to proportionally (Cohen and Klepper, 1996). In order to avoid unnecessary complexity, we simply assume that the proportion of R\&D investment depends proportionally on the firm size, and take it to be equal to a fraction $r$ of the current profit (firms that remain active only have positive profits).

The result of R\&D is an increase in the production efficiency of the firm. The efficiency increase is assumed to be equal to the invested amount. For an efficiency level $a_{t}$, the efficiency at the next time step will be:

$$
a_{t+1}=a_{t}+r \Pi_{t}
$$

Firms then adjust their prices to consumer demand in order to increase their profits. Given the assumption of bounded rationality, firms neither know the demand function of the consumers nor the prices of their competitors. They adjust their price through a myopic optimization process:

$$
p_{t+1}=p_{t}+\left(p_{t}-l_{t}\right)(1+m)^{H\left\{\log \left(\frac{p_{t}}{p_{t-1}}\right)\left(q_{t} p_{t}-l_{t-1}-\Pi_{t-1}\right)\right\}}, 0<m<1,
$$

where $H$ is a function that determines the sensitivity to profit change. It needs to be increasing an following the sign of its argument. To avoid unstable price adjustment processes, we also require it to be between -1 and 1 . This adjustment process means that firms follow the variation of the profit they make to adjust their prices. If a positive or negative price adjustment leads to a profit increase, firms will again adjust their price in the same direction. Note that firms optimize without taking the last efficiency improvement into account. This is in order to separate the effect of efficiency improvement from the effect of price variation of consumer demand on the change of profit.

We finally reallocate consumer's incomes according to the revenues of local firms and expenditures of local consumers. Given that firms only employ local labor and their owners also belong to the city, all the revenues they generate remains in their cities:

$$
C_{j, t+1}=\sum_{i \text { in city } j}\left(\sum_{\text {cities g }} p_{i g, t} q_{i g, t}\right) \text {. }
$$

\section{Results and discussion}

Given the difficulty to solve the model analytically, we resort to numerical simulations in order to explore the different outcomes of the model. We only explore the effect of three 
parameters, the others are left unchanged throughout the exploration, their values are given in Table 1.

\begin{tabular}{|l|c|}
\hline \multicolumn{1}{|c|}{ Parameter } & Value \\
\hline Initial number of cities $V$ & 30 \\
\hline Total number of industries $I$ & 100 \\
\hline Number of related industries & 4 \\
\hline Cities' initial income $C_{0}$ & 500 \\
\hline Perimeter of the circle $L$ & 2 \\
\hline Necessary quantity of fixed labor $b_{i}$ & 5 \\
\hline Firms' sensitivity to profit $m$ & 0.1 \\
\hline R\&D (profit) intensity $r$ & 0.05 \\
\hline Price guiding function $H$ & $H(x)=2 \pi^{-1} \arctan (0.5 \pi x)$ \\
\hline
\end{tabular}

Table 1: Constant parameter values used in all the simulations

The focus of the exploration is on the price competition $(\alpha)$, distance friction $(\gamma)$ and the probability of discovering a new industry $\left(p_{\text {disc }}\right)$. For each combination of parameters, 100 runs have been performed in order to evaluate the robustness of the result. Each run was performed for the number of steps that was necessary to discover all the industries, plus 50 extra steps to allow the stabilization of the dynamics.

We explore the results for the number of remaining cities at the end of the simulations (Figure 8-A), the value of mean slope coefficient of the log-size distribution (Figure 8-B), and the value of mean slope coefficient of the relation between city size and specialization (Figure 8-C). We preformed preliminary runs in order to determine the intervals over which the exploration was done. We find that for a level of competition that is high enough $(\alpha \geqslant 1.5)$, the evolution of the system ends with a unique city concentrating all active firms and the sum of all the cities' initial incomes. Similarly, for high values of the distance friction $(\gamma \geqslant 2)$, the final number of cities is lower than half of initial number.

The parameters for which the effect of variation is explored are the level of price competition $\alpha$, the level of distance friction $\gamma$, and the probability to discover a new industry $p_{\text {disc }}$. The parameters' values for exploration are chosen so that the cases with too few remaining cities are avoided. The explored values can be found in Table 2.

\begin{tabular}{|l|c|}
\hline \multicolumn{1}{|c|}{ Parameters } & Chosen values \\
\hline Level of price competition $\alpha$ & $0.2,0.4,0.6,0.8,1$ \\
\hline Distance friction $\gamma$ & $0,0.5,1,1.5,2$ \\
\hline Probability of discovering a new industry $p_{\text {disc }}$ & $0.05,0.1,0.2$ \\
\hline
\end{tabular}

Table 2: Chosen values for the model exploration.

The level of price competition $\alpha$ determines the importance of the relative price for the consumers when they choose among different products offered by firms belonging to a same industry. A High level of $\alpha$ means that consumers will give a considerable importance to the relative price of the different products when buying them. On the contrary, a low value of $\alpha$, means that the price is of little importance in determining the choice of consumers.

The distance friction parameter $\gamma$ determines the variation of the transportation cost with respect to the distance over which the products are carried. Given that transportation costs are at the charge of the producing firms, higher values of $\gamma$ raise further located firms' trading 
costs, decreasing their competitiveness compared to closer located firms. In the exploration, the particular case of the absence of transportation cost $(\gamma=0)$ is considered, along with three other forms of transportation costs: sublinear $(\gamma<1)$, linear $(\gamma=1)$, and super-linear $(\gamma>1)$.

The model is explored for different values of the probability $p_{\text {disc }}$ of discovering a new industry. In combination with the relatedness of the industries present in a given city, the $p_{\text {disc }}$ value determines the probability that a firm belonging to an inexistent industry enters in a city, conferring it a competitive advantage during the time step it enters. High values of $p_{\text {disc }}$ mean more frequent discoveries of industries, however this does not allow cities to host totally unrelated new industries.

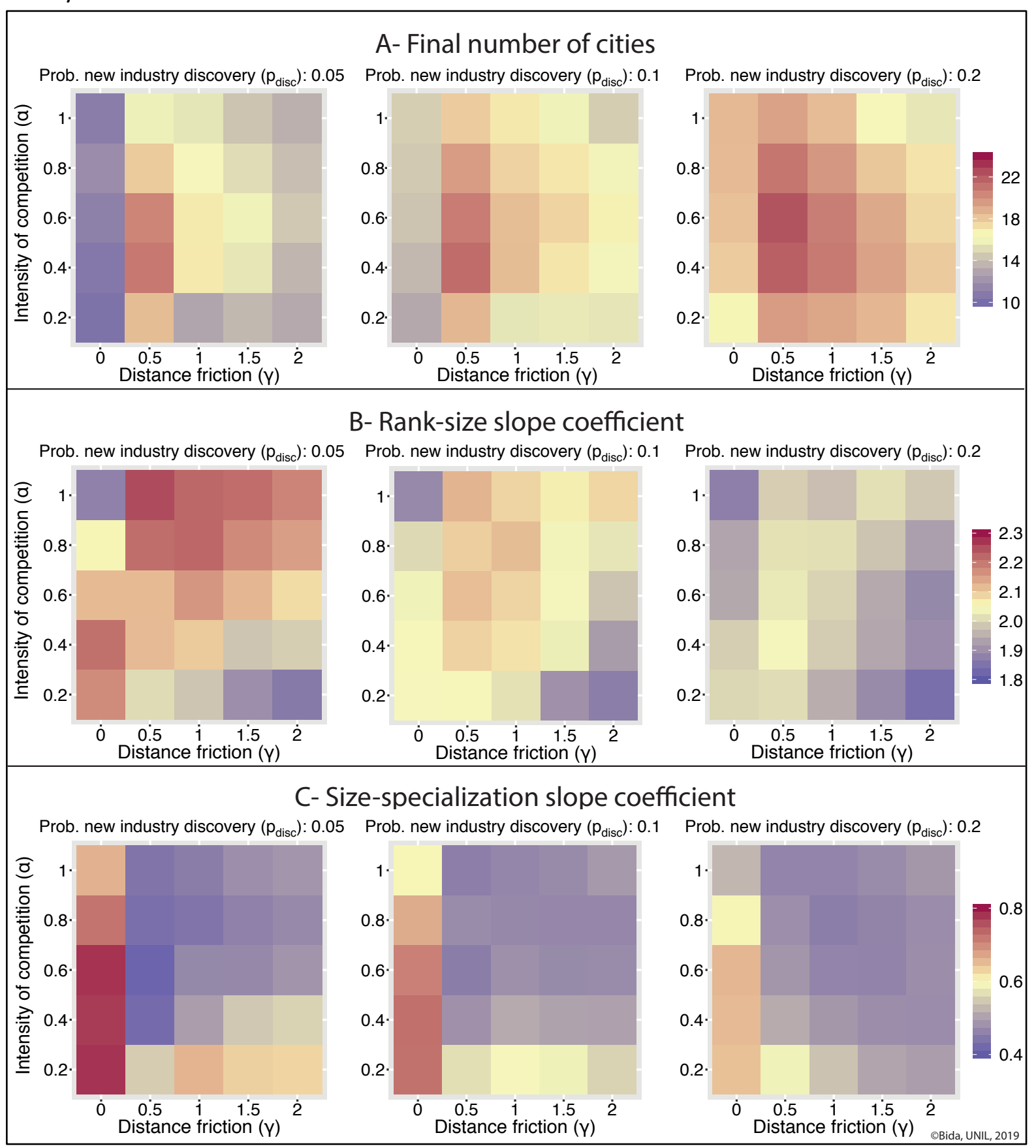

Figure 8: Average results of the cities' system simulations (100 simulations for each parameters combination) 


\subsection{Number of remaining cities}

For all the tested parameters combinations, the average number of remaining cities was computed (Figure 8-A). Recalling that the initial number of cities is 30 , this number can only decrease through the time steps. For none of the combinations, the final number of cities was found to remain the same as the initial number. The result becomes globally more robust to random fluctuations with the average final number of cities of the 100 runs (for each combination), where we observe a standard deviation from $24 \%$ for lowest mean value to $11 \%$ for the highest mean value. The final number of cities seems to increase with $p_{d i s c}$. However, the pattern seems to be non-monotonic for the combination of the parameters $\alpha$ and $\gamma$. The number seems to reach a maximum for low-intermediate values of the level of competition and distance friction. A moderate level of competition and distance friction seems to favor the maintenance of cities, possibly by allowing some profits and a certain level of production efficiency for larger cities, and a level of protection from outside competitors for less efficient firms in smaller cities. The lowest average final number of 10 cities was found for the combination $\left(\alpha=0.2, \gamma=0, p_{\text {disc }}=0.05\right)$. If a low transportation cost is not surprising, since it exposes less efficient producers to competition, the low value of price competition is less expected. We think that when the level of competition within a same industry is low, it is the interindustry competition that determines the growth of cities. In this case, larger cities, because they are more diversified gain an important advantage and "absorb" smaller, less diversified cities.

\subsection{City size distribution}

One of the main goals of the model is to generate the empirically observed Zipf distribution of cities. An example of resulting city size distribution is given with the parameters $\alpha=0.5, \gamma$ $=1$, and $p_{\text {disc }}=0.2$ (Fig.9).

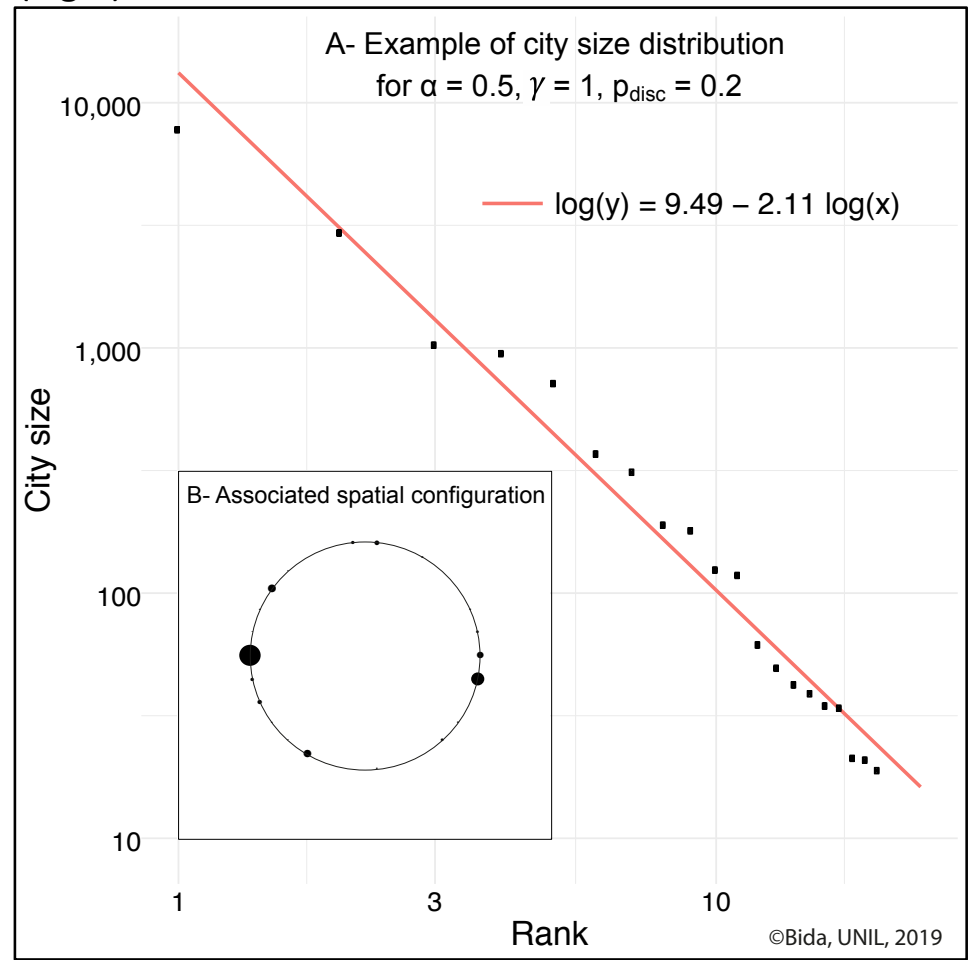

Figure 9: Example of city size distribution for one simulation 
For all the parameters' combinations, we estimate slope $-\beta_{1}$ between the logarithm of the city income $C$ and size rank $\rho$ using least squares:

$$
\underset{\beta_{0}, \beta_{1}}{\operatorname{argmin}} \sum_{C_{j}>0}\left[\log \left(C_{i}\right)-\beta_{0}-\beta_{1} \log \left(\rho_{i}\right)\right]^{2}
$$

For the range of the explored parameters, the model seems to perform qualitatively reasonably well, with an explained variance ranging between 0.9 and 0.97 . Moreover, over the 100 runs, for any parameters' combination, the standard deviation of the explained variance is below $6.2 \%$.

The resulting values of the slopes (Figure 8-B) range between 1.8 and 2.2, which is high compared to the empirically observed distributions (typical real city size distribution slopes range from 0.48 to 1.22 (Brakman et al., 2009)). Accounting for congestion costs due to city size could allow to reach more realistic values of slope of the rank size distribution as in (Brakman et al., 1999). Other options can also be considered, such as the inclusion of a nontraded industry in each city, that would prevent excessive shrinking of small cities as in Sanders et al. (1997), Duranton (2007), or in a more general way in Gabaix (1999).

As for the influence of the parameters on the slope, again, we observe that higher values seem to monotonically change the outcome by decreasing the size hierarchy of cities. The level of competition $\alpha$ seems to have a higher importance than the distance friction $\gamma$ when the latter has positive values. Higher level of competition allows larger firms and more efficient firms to better compete, enhancing the positive feedback loop between size and efficiency. Interestingly, when transportation costs are absent $(\gamma=0)$, a city size hierarchy is still observed, but the influence of the level of competition seems to have an opposite effect to the case of existing transportation costs. The same cause as the observed effect on size can be the reason: when the level of intra-industry competition is low, inter-industry competition favors the growth of larger, more diversified cities. Thus intra-industry competition seems so play a mitigating effect for the advantage of larger cities, possibly because smaller specialized cities host more efficient firms.

\subsection{Size-specialization relation}

The second main objective of the model is to reproduce the observed relation between size and specialization. In order to study the relation between city size and specialization, we use the Hirschmann-Herfindahl index $(\mathrm{HHI})$ to calculate the specialization level of each city $j$ :

$$
H H I(j)=\sum_{\text {industries } l}\left(\frac{\sum_{\text {firms } i \text { of } l \text { in } j} \Pi_{i}}{\sum_{\text {in } j} \Pi_{i}}\right)^{2} \text {. }
$$

The $\mathrm{HHI}$ index is widely used as concentration measure in general and as a measure of cities economic specialization in particular (e.g. Henderson, 1997). Lower values of the HHI index stand for a more diversified city. Cities with lower $\mathrm{HHI}$ index values are hosting a higher number of industries, of which size are more similar. An example of resulting city size distribution is given with the parameters $\alpha=0.5, \gamma=1$, and $p_{\text {disc }}=0.2$ (Fig.10). 


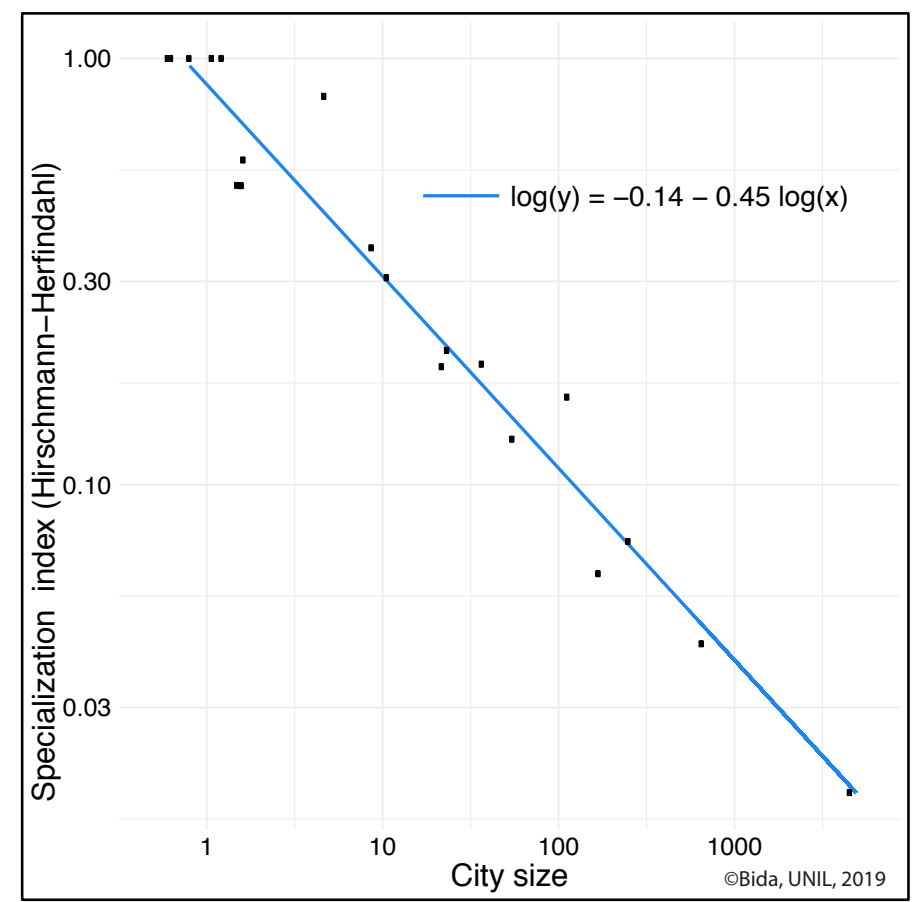

Figure 10: Example of size-specialization relation for $\alpha=0.5, \gamma=1$, and $p_{\text {disc }}=0.2$.

As previously, we find using least squares, the average linear relation between the logarithm of the $\mathrm{HHI}$ and the logarithm of the city sizes, given the 100 simulations for each parameter combination (here taken as the sum of profit making local firms). Here again, for the range of the explored parameters, the model seems to perform qualitatively reasonably well. For all parameters' combinations the relation between size and specialization is negative. The negative relation seems to be robust to random fluctuations for all parameters' combinations, with a maximum standard deviation of $24 \%$. The log linear model seems to yield a good fit with a minimum average explained variance of 0.85 . The model is thus an idealized case, as, to our knowledge, no empirical observation has revealed such a great regularity.

We observe that low levels of intra-industry competition favor a higher differentiation in economic specialization. This is consistent with the previous given explanation concerning the mitigating effect of intra-industry competition. Lower values of intra-industry competition seem to give more importance to inter-industry competition, intensifying the positive feedback between the size and the diversity of a city.

\subsection{Synthesis}

For all the explored parameters' combinations, the generated system of cities qualitatively matches the empirically observed features of real systems of cities concerning the hierarchization in size and economic specialization. The results have shown that the interaction between the three variables of the model can lead to non-monotonic effects when varying them. We note here that the interplay between intra-industry and inter-industry competition seems crucial in determining the final features of the system of cities. Interestingly, we also note that the expected hierarchization according to size and economic specialization is generated for both the cases of existent and absent transportation costs.

An important result is the low negative effect in general of the probability of new industry discovery $\left(p_{\text {disc }}\right)$ on the Rank-Size coefficient. In the SIMPOP model, the formation of the cities' 
hierarchy was only with the apparition of new innovations (Bura, 1996; Sanders, 1997). In the model we propose, the apparition of new industry is also necessary to create the cities' hierarchy. Our model shows however that raising the likelihood of apparition of new industries does not necessarily result in an increase of the cities' hierarchy. On the contrary, in the model presented here, increasing the likelihood of apparition of new industries benefits to all the existing cities, and thus mitigates their hierarchization. Thus, despite the fact that the model includes in a way, the hierarchical diffusion of innovations from largest cities to the smaller ones (Pumain, 2006b) because when a new industry appears in a city, the other cities can catch it during the following steps, the model seems however to over-estimate the speed of this diffusion. These spatial waves of diffusion of innovations are the result of economic cycles of which mechanisms and manifestations (Dosi and Nelson, 2010; Klepper, 1997) need to be better reproduced by the model.

\section{Conclusion}

We proposed in this chapter a micro-founded economic model, able to reproduce two main properties of system of cities considering the size distribution and the economic specialization. Relaxing the less realistic assumptions of main stream economic models, the model rests upon bounded rationality (Myopic optimization) and evolving firms' capabilities. In line with the recent findings of evolutionary economic geography, the model features path dependence through a process compatible with the idea of related diversification. Cities' industrial diversification is the result of past firms' interactions, and this diversification in turn constrains future firms' dynamics.

Starting from undifferentiated cities in terms of size and economic specialization, the model managed to generate a system of unequal cities by their size and their specialization. The obtained rank-size slopes depend largely on the combination of the level of intra-industry competition and the distance friction (but there is a low effect of the average probability of innovation). Simulation results also underlined the role of diversification of cities (several industries), especially when transportation costs are virtually inexistent.

However, the model lacks parts of complexity, given that several parameters that must evolve like in "real" urban system remain constant. For example, the sum of all cities' income is assumed to be constant. This restrains the expansion of the whole system, and thus the growth of cities and the diversification of their industries. Another simplification made in the model that deserves more attention is the structure of the industry space. Our results are valid for a particular simple structure of the industry space. This calls for further improvements to make the results robust to less regular and more conformable to realistic structures of the industry space.

Eventually, despite the qualitative similarity of the cities size distribution with real empirical observations, the range of the slope generated by the model is unrealistic. This might come from the lack of inclusion of several processes like non-traded local services, or congestion. This would allow to reproduce existing cities' systems in order to better understand their properties. In particular, it would be interesting to develop this model to study more applied questions as the effect of the intensity and forms of collaborations between firms on the 
features of the system of cities. Especially we are concerned by searching how to improve spatial organization of cities compatible with the contemporary challenges of sustainability.

\section{References}

Aydalot, P. (1985) Économie régionale et urbaine. Paris: Economica.

Batty, M. (2007) Cities and Complexity: Understanding Cities with Cellular Automata, Agent-Based Models, and Fractals. The MIT Press.

Boschma, R. (2017) Relatedness as driver of regional diversification: a research agenda. Regional Studies 51(3): 351-364.

Boschma, R., and Frenken, K. (2011) Technological Relatedness and Regional Branching. In Bathelt, H., Feldman, M. P., and Kogler, D. F. (Eds.), Beyond Territory: Dynamic Geographies of Knowledge Creation, Diffusion and Innovation. Routledge.

Boschma, R., and Martin, R. (2010) The Handbook of Evolutionary Economic Geography. Edward Elgar Publishing doi:10.4337/9781849806497.

Brakman, S., Garretsen, H., and van Marrewijk, C. (2009) The New Introduction to Geographical Economics. (2nd ed.). Cambridge: Cambridge University Press doi:10.1017/CBO9780511818745.

Brakman, S., Garretsen, H., Van Marrewijk, C., and Van Den Berg, M. (1999) The Return of Zipf: Towards a Further Understanding of the Rank-Size Distribution. Journal of Regional Science 39(1): 183-213.

Bura, S., Guérin-Pace, F., Mathian, H., Pumain, D., and Sanders, L. (1996) Multiagent Systems and the Dynamics of a Settlement System. Geographical Analysis 28(2): 161-178.

Christaller, W. (1933) Die zentralen Orte in Süddeutschland: Eine ökonomisch-geographische Untersuchung über die Gesetzmässigkeit der Verbreitung und Entwicklung der Siedlungen mit städtischen Funktionen. Gustav Fischer, Jena.

Cohen, W. M. (2010) Fifty Years of Empirical Studies of Innovative Activity and Performance. In Hall, B. H. and Rosenberg, N. (Eds.), Handbook of the Economics of Innovation (Vol. 1). North-Holland.

Cohen, W. M., and Klepper, S. (1996) A Reprise of Size and R \& D. The Economic Journal 106(437): 925-951.

Davis, D. R., and Dingel, J. I. (2014) The Comparative Advantage of Cities, Working Paper No. w20602. National Bureau of Economic Research doi:10.3386/w20602.

Dimou, M., and Schaffar, A. (2011) Les théories de la croissance urbaine, Urban growth theories. Revue d'économie politique 121(2): 179-207.

Dosi, G., and Nelson, R. R. (2010) Technical Change and Industrial Dynamics as Evolutionary Processes. In Hall, B. H. and Rosenberg, N. (Eds.), Handbook of the Economics of Innovation (Vol. 1). North-Holland.

Duranton, G. (2007) Urban Evolutions: The Fast, the Slow, and the Still. The American Economic Review 97(1): 197-221.

Duranton, G., and Puga, D. (2000) Diversity and specialisation in cities: why, where and when does it matter? Urban studies 37(3): 533-555.

Eaton, J., and Eckstein, Z. (1997) Cities and growth: Theory and evidence from France and Japan. Regional Science and Urban Economics 27(4): 443-474.

Gabaix, X. (1999) Zipf's Law for Cities: An Explanation. The Quarterly Journal of Economics 114(3): 739-767. 
Giesen, K., and Suedekum, J. (2012) The Size Distribution across all 'Cities': A Unifying Approach, Working Paper No. 3730. CESifo Group Munich.

Henderson, V. (1997) Medium size cities. Regional Science and Urban Economics 27(6): 583-612.

Hidalgo, C. A., Klinger, B., Barabási, A.-L., and Hausmann, R. (2007) The Product Space Conditions the Development of Nations. Science 317(5837): 482-487.

Klepper, S. (1997) Industry Life Cycles. Industrial and Corporate Change 6(1): 145-182.

Krugman, P. (1991) Increasing Returns and Economic Geography. Journal of Political Economy 99(3): 483-499.

Ladyman, J., Lambert, J., and Wiesner, K. (2013) What is a complex system? European Journal for Philosophy of Science 3(1): 33-67.

Lane, D., Pumain, D., Leeuw, S. E. van der, and West, G. eds. (2009) Complexity Perspectives in Innovation and Social Change. Springer Netherlands.

Marshall, J. U. (1981) Industrial Diversification in the Canadian Urban System. Canadian Geographer / Le Géographe canadien 25(4): 316-332.

Mills, E. S. (1967) An Aggregative Model of Resource Allocation in a Metropolitan Area. The American Economic Review 57(2): 197-210.

Min-rong, C., and Yan-hua, M. (2013) Specialization and diversification in cities: The evidence from China. In 2013 6th International Conference on Information Management, Innovation Management and Industrial Engineering (Vol. 1). Presented at the 2013 6th International Conference on Information Management, Innovation Management and Industrial Engineering.

Mori, T., Nishikimi, K., and Smith, T. E. (2008) The Number-Average Size Rule: A New Empirical Relationship Between Industrial Location and City Size. Journal of Regional Science 48(1): 165-211.

Neffke, F., Henning, M., and Boschma, R. (2011) How Do Regions Diversify over Time? Industry Relatedness and the Development of New Growth Paths in Regions. Economic Geography 87(3): 237-265.

Nelson, R. R., and Winter, S. G. (1982) An evolutionary theory of economic change. Cambridge, Massachusetts: The Belknap Press of Harvard University Press.

Portugali, J. (2011) Complexity, Cognition and the City. Berlin Heidelberg: Springer-Verlag.

Pumain, D. ed. (2006a) Hierarchy in natural and social sciences. Dordrecht, The Netherlands:

Springer.

Pumain, D. (2006b) Alternative Explanations of Hierarchical Differentiation in Urban Systems. In Hierarchy in Natural and Social Sciences. Springer, Dordrecht doi:10.1007/1-4020-4127-6_8.

Pumain, D. (2012) Multi-agent System Modelling for Urban Systems: The Series of SIMPOP Models. In Heppenstall, A., Crooks, A., and Batty, M. (Eds.), Agent-Based Models of Geographical Systems. Springer, Dordrecht doi:10.1007/978-90-481-8927-4_36.

Pumain, D., Paulus, F., and Vacchiani-Marcuzzo, C. (2009) Innovation Cycles and Urban Dynamics. In Lane, D., Pumain, D., van der Leeuw, S. E., and West, G. (Eds.), Complexity Perspectives in Innovation and Social Change. Springer doi:10.1007/978-1-4020-9663-1_9.

Pumain, D., and Reuillon, R. (2017) Urban Dynamics and Simulation Models. Springer International Publishing doi:10.1007/978-3-319-46497-8.

Rosen, K. T., and Resnick, M. (1980) The size distribution of cities: An examination of the Pareto law and primacy. Journal of Urban Economics 8(2): 165-186.

Sanders, L., Pumain, D., Mathian, H., Guérin-Pace, F., and Bura, S. (1997) SIMPOP: a multi-agent system for the study of urbanism. Environment and Planning B: Planning and Design (24): 287-305. 
Singer, H. W. (1936) The 'Courbe des Populations.' A Parallel to Pareto's Law. The Economic Journal 46(182): 254-263.

Tabuchi, T., and Thisse, J.-F. (2011) A new economic geography model of central places. Journal of Urban Economics 69(2): 240-252.

Thompson, P. (2010) Learning by Doing. In Hall, B. H. and Rosenberg, N. (Eds.), Handbook of the Economics of Innovation (Vol. 1). North-Holland.

Zipf, G. K. (1949) Human behavior and the principle of least effort. (Addison-Wesley Press.). 